\title{
Development and Validation of a Predictive Model of Success in Bariatric Surgery
}

\author{
Carina A. Blume ${ }^{1}$ (1) - Priscila G. Brust-Renck ${ }^{2,3} \cdot$ Miriam K. Rocha $^{3,4} \cdot$ Gabriel Leivas $^{5}$ - Jeruza L. Neyeloff ${ }^{6}$ \\ Michel J. Anzanello ${ }^{3}$ • Flavio S. Fogliatto ${ }^{3}$ - Luciana R. Bahia ${ }^{6}$ - Gabriela H. Telo ${ }^{7}$ Beatriz D. Schaan ${ }^{1,6,8}$
}

Received: 15 July 2020 / Revised: 28 October 2020 / Accepted: 29 October 2020 / Published online: 14 November 2020

(C) Springer Science+Business Media, LLC, part of Springer Nature 2020

\begin{abstract}
Purpose There are no criteria to establish priority for bariatric surgery candidates in the public health system in several countries. The aim of this study is to identify preoperative characteristics that allow predicting the success after bariatric surgery.

Materials and Methods Four hundred and sixty-one patients submitted to Roux-en-Y gastric bypass were included. Success of the surgery was defined as the sum of five outcome variables, assessed at baseline and 12 months after the surgery: excess weight loss, use of continuous positive airway pressure (CPAP) or bilevel positive airway pressure (BiPAP) as a treatment for obstructive sleep apnea (OSA), daily number of antidiabetics, daily number of antihypertensive drugs, and all-cause mortality. Partial least squares (PLS) regression and multiple linear regression were performed to identify preoperative predictors. We performed a 90/ 10 split of the dataset in train and test sets and ran a leave-one-out cross-validation on the train set and the best PLS model was chosen based on goodness-of-fit criteria.

Results The preoperative predictors of success after bariatric surgery included lower age, presence of non-alcoholic fatty liver disease and OSA, more years of CPAP/BiPAP use, negative history of cardiovascular disease, and lower number of antihypertensive drugs. The PLS model displayed a mean absolute percent error of 0.1121 in the test portion of the dataset, leading to accurate predictions of postoperative outcomes.

Conclusion This success index allows prioritizing patients with the best indication for the procedure and could be incorporated in the public health system as a support tool in the decision-making process.
\end{abstract}

Keywords Bariatric surgery $\cdot$ Roux-en-Y gastric bypass $\cdot$ Waiting list $\cdot$ Public health $\cdot$ Waiting time $\cdot$ Scoring system

Beatriz D. Schaan

bschaan@hcpa.edu.br

Carina A. Blume

carinablume@hotmail.com

Priscila G. Brust-Renck

prirenck@gmail.com

Miriam K. Rocha

miriam.rocha@ufersa.edu.br

Gabriel Leivas

gleivas@hcpa.edu.br

Jeruza L. Neyeloff

jneyeloff@hcpa.edu.br

\author{
Michel J. Anzanello \\ anzanello@producao.ufrgs.br \\ Flavio S. Fogliatto \\ ffogliatto@producao.ufrgs.br \\ Luciana R. Bahia \\ lucianabahia@gmail.com \\ Gabriela H. Telo \\ gtelo.endocrinologia@gmail.com
}

Extended author information available on the last page of the article 


\section{Introduction}

Obesity is a major risk factor for noncommunicable diseases and its prevalence has substantially increased in the past decades, leading to a reduced life expectancy worldwide [1-3]. Bariatric surgery has emerged as an effective treatment for sustained weight loss and long-term improvement in obesity-related diseases $[4,5]$. Surgically induced weight loss is indicated for individuals with a body mass index $(\mathrm{BMI}) \geq 40 \mathrm{~kg} / \mathrm{m}^{2}$ or a $\mathrm{BMI} \geq 35 \mathrm{~kg} / \mathrm{m}^{2}$ with at least one related comorbidity, such as type 2 diabetes mellitus, hypertension, obstructive sleep apnea syndrome (OSA), and non-alcoholic fatty liver disease (NAFLD) [6].

Despite the growing rate in the number of bariatric surgeries performed each year, the demand is greater than the capacity in several countries, with waiting times of up to 5 years [7-10]. Delaying bariatric surgery was associated with a 3fold mortality increase and appears to be a more expensive strategy than prompt surgery from the Brazilian public health system perspective $[8,11]$. In a modeling study with a 20 -year time horizon, waiting 7 years for the procedure compared to performing surgery immediately was the most expensive and least effective strategy [8].

There are no current criteria to establish priority for bariatric surgery candidates in the Brazilian public health system and the waiting time regime adopts a first-in-first-out queue rule. Few scoring systems have been developed, mostly assessing early postoperative mortality predictors or longterm mortality predictors including individuals with overweight and obesity that have not undergone bariatric surgery [12-15].

Considering that bariatric surgery is an elective procedure but with a significant impact on morbidity and mortality, the identification of patients who would obtain the greatest benefits is essential in order to organize the access to surgery. The aim of this study is to identify preoperative predictors of postoperative success, here defined as the sum of five outcome variables, four assessed at baseline and 1 year after the surgery, and one outcome assessed only after the surgery (all-cause mortality). We developed and validated a statistical model based exclusively on patients' preoperative characteristics that allows predicting the success after bariatric surgery and prioritizing patients with the best indication for the procedure.

\section{Materials and Methods}

\section{Setting and Study Population}

This is a retrospective cohort study including all patients who have undergone bariatric surgery from January 2010 to December 2017 at a tertiary care teaching public hospital in
Porto Alegre, Southern Brazil. Roux-en-Y gastric bypass (RYGB) is the only bariatric technique performed in this hospital. The same surgical team performed all surgeries. This study was approved by the local Ethics Committee (20180088) and informed consent was not required to conduct this secondary data analysis. Brazil has a publicly funded universal health care system and the hospital is a reference for all medical care at State level (approximately 11.3 million people). Data were selected from hospital's records at the time patients conducted initial exams to be considered eligible for bariatric surgery up to 1 year after the surgery. This study followed the recommendations of the Transparent Reporting of a Multivariable Prediction Model for Individual Prognosis Or Diagnosis (TRIPOD) [16].

\section{Measures and Outcomes}

Success of the surgery was defined as the sum of the following five outcome variables, detailed in Table 2 and in the Supplemental Material: (R1) excess weight loss using a BMI of $25 \mathrm{~kg} / \mathrm{m}^{2}$ as a reference for ideal body weight [17], (R2) use of continuous positive airway pressure (CPAP) or bilevel positive airway pressure (BiPAP) as a treatment for OSA, (R3) daily use of antidiabetics (including insulin), (R4) daily use of antihypertensive medication, and (R5) all-cause mortality. Follow-up measures were obtained from patients' scheduled appointments. The choice of the five variables for our composite clinical success score relies on well-reported outcomes after bariatric surgery. In addition to weight loss, the surgery is associated with lower all-cause mortality [18], improvement or remission of type 2 diabetes mellitus [4, 19], hypertension [20, 21], and OSA [22], here assessed by the reduction of the total number of antidiabetic and antihypertensive drugs and CPAP/BiPAP discharge 1 year postoperative, respectively.

Although success outcome variables R1 to R4 were measured at baseline and 1 year after the surgery, data on the following predictors were only assessed at baseline: BMI $\left(\mathrm{kg} / \mathrm{m}^{2}\right)$, initial excess weight in $\mathrm{kg}$ (based on a BMI of $25 \mathrm{~kg} / \mathrm{m}^{2}$ ), age, gender, marital status, skin color, educational level, waiting time for surgery (since being eligible) in months, self-reported alcoholism and smoking status, hypertension [23], type 2 diabetes mellitus [24], hypercholesterolemia [25], OSA syndrome defined according to the preoperative polysomnography test and/or CPAP or BiPAP use [26], NAFLD defined by the liver biopsy (routinely performed at the same surgical time or by preoperative abdominal ultrasound) [27, 28], history of cardiovascular disease, gastroesophageal reflux and osteoarthritis defined by medical report, major depressive disorder defined by psychiatric report, the amount of daily 
antidiabetic, antihypertensive and lipid-lowering drugs, and laboratory data: fasting glucose $(\mathrm{mg} / \mathrm{dL})$, total cholesterol (mg/dL), HDL-cholesterol (mg/dL), LDL-cholesterol $(\mathrm{mg} / \mathrm{dL})$, triglycerides $(\mathrm{mg} / \mathrm{dL})$, and creatinine $(\mathrm{mg} / \mathrm{dL})$.

\section{Statistical Analysis}

Patient records with missing information on clinical variables were pre-treated using the k-nearest-neighbor $(\mathrm{KNN})$ imputation method from Matlab. An optimal scaling technique from IBM SPSS Statistics, version 18, was used for recoding all numerical, nominal, and categorical variables. We ran a crossvalidation leave-one-out model of the partial least squares (PLS) regression using Matlab's iToolbox to compare the imputed $(n=461)$ and the original dataset without missing data $(n=277)$ to predict success including all preoperative predictors.

We performed a 90/10 split of the dataset in train and test sets using the Kennard-Stone technique. Next, we ran a leaveone-out cross-validation procedure on the train set and the best PLS model was chosen based on goodness-of-fit criteria. The best model is then applied to the test set and the final root mean square error (RMSE) measure was determined. A multiple linear regression (MLR) model was performed with stepwise variable selection using the success index as dependent variable and the same predictors tested in the PLS regression, all measured at baseline. The MLR analysis allowed determining the significance of predictors, which is not available from the PLS model.

Additionally, baseline and 1-year post-RYGB characteristics were compared using Student's paired $t$ test or McNemar test and $p$ values (two-tailed) of $<0.05$ were considered significant. Quantitative data were shown as mean and standard deviation (SD) or median and interquartile range. Spearman or Pearson correlation analyses were performed on all laboratory data using the difference score from baseline to one-year postRYGB.

\section{Results}

The complete dataset included 461 patients, mostly female $(84.6 \%)$, white $(89.4 \%)$, with a mean age of $42.3 \pm 10.8$ years. The sample consisted mostly of married/cohabiting (47.1\%) and single $(43.8 \%)$ subjects, with a small proportion of divorced (6.7\%) and widowed (2.4\%) individuals. Most patients had middle school education or less $(48.4 \%), 39.1 \%$ had started or completed high school, and $12.5 \%$ had started or achieved a graduate degree. Preoperative BMI ranged from 35.0 to $89.2 \mathrm{~kg} / \mathrm{m}^{2}$ with a median excess weight of $61.4(48.5-77.5) \mathrm{kg}$. Self-reported mean duration of obesity (defined as a BMI $\geq 30 \mathrm{~kg} / \mathrm{m}^{2}$ ) was $18.7 \pm 9.6$ years. Median waiting time for surgery was 30 months [21-41].
Excess weight loss 1 year postoperative was $68.6 \pm$ $17.3 \%$. Table 1 presents the baseline and 1 -year postRYGB clinical and laboratory characteristics. Mortality records sometimes went beyond the 1-year follow-up, but all-cause mortality was low $(n=17)$; of those, eight deaths were related to obesity or surgery complications (sepsis, bronchospasm, hypovolemic shock, and respiratory failure).

Table 2 presents the outcome variables and success index after bariatric surgery. The PLS regression for the data with missing values and the imputed dataset indicated a good fit of the later based on mean absolute percent error (MAPE- a robust to outliers, relative measure of error that compares the model's predictions fit to the corresponding outputs based on the absolute value of the residuals) of 0.112 , compared to 0.114 with missing, and root mean square error (RMSEmeasure of how much the results are affected by the residuals based on the square root of their absolute value) of 0.471 , compared to 0.408 with missing. All subsequent analyses were performed on the imputed dataset.

PLS and MLR models were adjusted to the imputed dataset, considering all-cause mortality (models considering only deaths due to obesity or surgery complications resulted very similar and are not shown here). In Table 3, we present models' statistics and results; only predictors displaying absolute PLS loads greater than 0.3 and/or MLR significance 0.05 or smaller are included. We identified a trend association between the predictive success model and the improvement in metabolic parameters such as fasting blood glucose $(r=$ -0.166; $p<.001)$, HDL-cholesterol $(r=0.107 ; p=.002)$, and triglycerides $(r=-0.139 ; p=.003)$.

Table 4 presents the sample of patients divided in three similar sized groups after organized in ascending order according to a composite indicator that added the patient's success index value and four variables indicating the presence of four comorbidities, with binary outcomes $(1=$ presence; $0=$ absence).

\section{Discussion}

Eligibility criteria for bariatric surgery have been exclusively based on BMI since 1991 [6]. Despite overall mortality and most specific causes of death appear to be proportional to BMI increase [29], this approach has been criticized for more than a decade [30]. There are only a few scoring systems available in the literature, which assessed mostly predictors of mortality or complications related to the surgery [12-15, 31, 32]. Some of those scores evaluated individuals with overweight and obesity that have not undergone bariatric surgical procedures. More recently, experts from the Diabetes Surgery Summit consensus series developed a guidance for prioritization of bariatric and metabolic surgeries since most elective 
Table 1 Subjects' characteristics at baseline and 12 months after Roux-en-Y gastric bypass

\begin{tabular}{|c|c|c|c|}
\hline Characteristics & Baseline & 12 months & $p$ value \\
\hline \multicolumn{4}{|l|}{ Clinical characteristics } \\
\hline Body mass index, $\mathrm{kg} / \mathrm{m}^{2}$ & $49.7 \pm 8.7$ & $33.4 \pm 6.3$ & $<.001$ \\
\hline Current alcohol drinker & $3(0.7 \%)$ & $5(1.1 \%)$ & .261 \\
\hline Former alcohol drinker & $20(4.3 \%)$ & - & - \\
\hline Current smoker & $19(4.1 \%)$ & $16(3.5 \%)$ & .782 \\
\hline Former smoker & $125(27.1 \%)$ & - & - \\
\hline Systolic blood pressure (mmHg) & $136.5 \pm 16.4$ & $119.4 \pm 16.0$ & $<.001$ \\
\hline Diastolic blood pressure ( $\mathrm{mmHg}$ ) & $85.9 \pm 12.2$ & $75.7 \pm 11.3$ & $<.001$ \\
\hline Type 2 diabetes mellitus & $142(30.8 \%)$ & $33(7.2 \%)$ & $<.001$ \\
\hline Hypertension & $324(70.3 \%)$ & $164(35.6 \%)$ & $<.001$ \\
\hline Hypercholesterolemia & $216(46.9 \%)$ & $62(13.4 \%)$ & $<.001$ \\
\hline Obstructive sleep apnea syndrome (OSA) & $126(27.3 \%)$ & $\mathrm{NA}$ & - \\
\hline Mild OSA & $44(34.9 \%)$ & NA & - \\
\hline Moderate OSA & $29(23 \%)$ & NA & - \\
\hline Severe OSA & $53(42.1 \%)$ & NA & - \\
\hline CPAP or BiPAP use & $89(19.3 \%)$ & $48(10.4 \%)$ & $<.001$ \\
\hline CPAP or BiPAP use time (months) & $9.4(6-15.9)$ & - & - \\
\hline Non-alcoholic fatty liver disease* & $308(74.8 \%)$ & NA & - \\
\hline Hepatic steatosis & $204(66.2 \%)$ & NA & - \\
\hline Steatohepatitis & $104(33.8 \%)$ & NA & - \\
\hline Gastroesophageal reflux & $44(9.5 \%)$ & NA & - \\
\hline Major depressive disorder & $132(28.6 \%)$ & NA & - \\
\hline History of cardiovascular disease ${ }^{* *}$ & $31(6.8 \%)$ & NA & - \\
\hline Osteoarthritis & $84(18.3 \%)$ & NA & - \\
\hline \multicolumn{4}{|l|}{ Medication use } \\
\hline Oral antidiabetic drugs & $131(28.4 \%)$ & $31(6.7 \%)$ & $<.001$ \\
\hline \multicolumn{4}{|l|}{ No. of daily oral antidiabetic drugs } \\
\hline 1 & $82(62.6 \%)$ & $24(77.4 \%)$ & \\
\hline 2 & $41(31.3 \%)$ & $7(22.6 \%)$ & \\
\hline$\geq 3$ & $8(6.1 \%)$ & $0(0 \%)$ & \\
\hline Insulin use & $21(14.8 \%)$ & $2(6 \%)$ & .002 \\
\hline Antihypertensive drugs & $314(68.1 \%)$ & $145(31.5 \%)$ & $<.001$ \\
\hline \multicolumn{4}{|l|}{ No. of daily oral antihypertensive drugs } \\
\hline 1 & $94(29.9 \%)$ & $145(100 \%)$ & \\
\hline 2 & $130(41.4 \%)$ & $0(0 \%)$ & \\
\hline 3 & $58(18.5 \%)$ & $0(0 \%)$ & \\
\hline$\geq 4$ & $32(10.2 \%)$ & $0(0 \%)$ & \\
\hline Lipid-lowering drugs & $89(19.3 \%)$ & $43(9.3 \%)$ & $<.001$ \\
\hline \multicolumn{4}{|l|}{ Laboratory assessment } \\
\hline Fasting blood glucose (mg/dL) & $112.5 \pm 37.3$ & $86.5 \pm 14.7$ & $<.001$ \\
\hline Total cholesterol $(\mathrm{mg} / \mathrm{dL})$ & $186.2 \pm 36.3$ & $149.8 \pm 30.5$ & $<.001$ \\
\hline HDL-cholesterol (mg/dL) & $44.7 \pm 11.95$ & $49.0 \pm 11.9$ & $<.001$ \\
\hline LDL-cholesterol (mg/dL) & $110.8 \pm 32.0$ & $82.3 \pm 25.7$ & $<.001$ \\
\hline Triglycerides (mg/dL) & $154.0 \pm 77.9$ & $93.0 \pm 47.4$ & $<.001$ \\
\hline Creatinine $(\mathrm{mg} / \mathrm{dL})$ & $0.73 \pm 0.23$ & $0.66 \pm 0.18$ & $<.001$ \\
\hline
\end{tabular}

*84.4\% was defined by liver biopsy and $15.6 \%$ was defined by abdominal ultrasound

**Coronary arterial disease, ischemic heart disease, stroke, heart failure, and cor pulmonale

Data are presented as mean $\pm \mathrm{SD}$, median (interquartile range) or proportion $\mathrm{n}(\%) . p$ value significance level (two-tailed) for comparison using Student's paired $t$ test or McNemar test, NA data not available, BiPAP bilevel positive airway pressure, CPAP continuous positive airway pressure

procedures have been postponed during the coronavirus disease 2019 (COVID-19) pandemic. It is proposed to prioritize bariatric surgery for patients at increased risk for morbidity and mortality according to coexisting comorbidities, i.e., type 2 diabetes mellitus, non-alcoholic steatohepatitis, hypertension, severe OSA, severe obesity hypoventilation syndrome, heart failure, and chronic kidney disease. Noteworthy, the selection of patients by BMI was not considered to be the most appropriate. Despite the important discussion and the novelty raised by the authors this guidance is a personal view based on expert opinion [33].

To our knowledge, this is the first study that developed and validated a robust statistical model to predict success after a bariatric surgery using a composite indicator based exclusively on preoperative characteristics in a sample of patients who have undergone bariatric surgery. 
Table 2 Outcome variables and success index after bariatric surgery

\begin{tabular}{lll}
\hline Outcome variable & Scale & Mean (SD) \\
\hline R1-excess weight loss & Between 0 and 1 & $0.68(0.16)$ \\
R2 - required use of CPAP/BiPAP & Binary (0 or 1) & $0.10(0.30)$ \\
R3 - number of antidiabetic drugs* & Between 0 and 1 & $0.77(0.18)$ \\
R4 - number of antihypertensive drugs & Between 0 and 1 & $0.65(0.37)$ \\
R5 - all-cause mortality & Binary (0 or 1) & $0.98(0.13)$ \\
Success index (sum of responses) & Between 0 and 5 & $3.19(0.58)$ \\
\hline
\end{tabular}

R1: Excess weight loss was calculated using a BMI of $25 \mathrm{~kg} / \mathrm{m}^{2}$ as a reference. The gradient in BMI ( $\triangle B M I)$ was used to assess variable $(\mathrm{R} 1)$ : $\triangle \mathrm{BMI}=(\mathrm{BSBMI}-\mathrm{ASBMI}) /(\mathrm{BSBMI}-25)$

$\mathrm{R} 2$ : Value 1 was assigned to subjects who stopped using CPAP or BiPAP 1 year after RYGB; value 0 was assigned to those who did not require $\mathrm{CPAP}$ or BiPAP before surgery and to those who used it and continued using 1 year after surgery

R3: 1 - ratio between the daily number of prescribed antidiabetics used before and 1 year after surgery. Subjects who did not require antidiabetics at baseline and remained without medication 1 year postoperatively were given value 0.75

R4: 1 -ratio between the daily number of prescribed antihypertensive drugs used before and 1 year after surgery. Subjects who did not require antihypertensive medication at baseline and remained without medication 1 year postoperatively were given value 0.75

R5: Value 1 was assigned to subjects who did not die, and 0 , otherwise $A S B M I$ post-surgery BMI, BiPAP bilevel positive airway pressure, $B M I$ body mass index, $B S B M I$ pre-surgery BMI, $C P A P$ continuous positive airway pressure. *Oral antidiabetic drugs and/or insulin.

We found that the patients with a greater likelihood of a successful surgical outcome are younger, presenting preoperative NAFLD and OSA, more years of preoperative CPAP/BiPAP use, negative history of cardiovascular disease, and lower number of daily antihypertensive drugs. As

Table 3 Partial least squares loadings, multiple linear regression coefficients, and goodness-of-fit statistics of preoperative predictors of success after bariatric surgery

\begin{tabular}{llll}
\hline Preoperative predictor & $\beta$ & $p$ value & PLS load \\
\hline Age, years & -.22 & .0002 & .3775 \\
Non-alcoholic fatty liver disease & .11 & .0266 & .2242 \\
CPAP/BiPAP use time, years & .14 & .0418 & .3929 \\
Obstructive sleep apnea syndrome & .18 & .0074 & .4058 \\
Negative history of CVD & .11 & .0267 & .3140 \\
Number of antihypertensive drugs & -.13 & .0746 & .3912
\end{tabular}

PLS: 1 principal component retained, MAPE $=.1121, \mathrm{RMSE}=.4705$ MLR: $R^{2}=.182, \mathrm{RMSE}=.544$

Dependent variable: success index. Model considering all-cause mortality. Abbreviations: BiPAP bilevel positive airway pressure, $C P A P$ continuous positive airway pressure, $C V D$ cardiovascular diseases, $M A P E$ mean absolute percent error, $M L R$ multiple linear regression, $P L S$ partial least squares, $R M S E$ root mean squared error opposed to the conventional wisdom, a higher preoperative BMI did not predict the postoperative success index. The rationale could be that once a specific degree of obesity is established, the BMI becomes no longer an important predictor, as our sample was composed by $92 \%$ of individuals with preoperative BMI higher than $40 \mathrm{~kg} / \mathrm{m}^{2}$. This result is in line with previous evidence from larger samples assessing mortality predictors $[12,13]$. We found a low prevalence of preoperative cardiovascular disease $(6.8 \%)$ and this could explain the reason why negative history of cardiovascular disease was a predictor of greater success after surgery. Although bariatric surgery is associated to reduced cardiovascular risk, the prevalence of patients with a preoperative history is remarkedly low $[34,35]$. In the large Swedish Obese Subjects (SOS) study, only $1.5 \%$ candidates for bariatric surgery had a history of cardiovascular disease [35].

Padwal et al. [12] assessed predictors of 10-year all-cause mortality in a sample of 15,394 subjects eligible for bariatric surgery and identified a 4-variable clinical prediction rule that included higher age, male sex, type 2 diabetes mellitus, and current smoking. Even after sensitivity analysis, BMI was not an important mortality predictor. Another study evaluated the ability of the Edmonton Obesity Staging System (EOSS) to predict mortality among 7967 adults with overweight and obesity; of those, 1106 were candidates for bariatric surgery [13]. The EOSS is a 5-point ordinal classification system that considers comorbidities and functional limitations and/or impairment of well-being related to obesity. Scores of 2 (hazard ratio [HR] $1.57 ; 95 \% \mathrm{CI} 1.16$ to 2.13 ) and 3 (HR $2.69 ; 95 \% \mathrm{CI}$ 1.98-3.67) were associated with an increased mortality when compared to scores of 0 or 1 in both the overall population and the cohort eligible for bariatric surgery, independently of BMI. Patients' preferences were also considered regarding prioritization for bariatric surgery $[32,36]$. A Canadian study assessed the patients' perspectives and found clinical severity and functional impairments related to obesity as the main factors that should be considered in the prioritizing setting [36]. Despite the strengths of each approach, the first concern that emerges is that those scores addressed a population that has not undergone bariatric surgery. Secondly, the only outcome investigated in both scores mentioned above was mortality which requires a long-term follow-up. Thirdly, in order to prioritize the access to surgery, the assessment of functional status of all eligible patients waiting for the surgical treatment might be a challenge in clinical practice.

The metabolic effects of bariatric surgery on comorbidities extend beyond the excess weight loss and impacts on type 2 diabetes mellitus, dyslipidemia, and hypertension remission, improving the OSA and NAFLD severity and reducing the cardiovascular risk and overall mortality. Therefore, we developed and validated a composite score that comprises the sum of five outcome variables to best predict success in bariatric surgery according to the 
Table 4 Patients grouped in ascending order according to a composite indicator that considers a success index after bariatric surgery and the prevalence of preoperative comorbidities

\begin{tabular}{llllllll}
\hline Success & $N$ & Avg success index & $\begin{array}{l}\text { Composite } \\
\text { indicator }\end{array}$ & OSA & T2DM & Hypertension & BMI $>40$ \\
\hline Low & 154 & 2.50 & $2.50 ; 4.63$ & 3 & 7 & 55 & 132 \\
Medium & 153 & 3.26 & $4.63 ; 5.66$ & 27 & 36 & 127 & 142 \\
High & 154 & 3.75 & $5.66 ; 8.70$ & 96 & 99 & 142 & 150 \\
Total & 461 & & & 126 & 142 & 332 & 424 \\
\hline
\end{tabular}

Avg average, $B M I$ body mass index, $O S A$ obstructive sleep apnea syndrome, $T 2 D M$ type 2 diabetes mellitus literature $[4,5,19,20,22,37-39]$. Besides the excess weight loss and all-cause mortality, we assessed the reduction of the total number of antidiabetic and antihypertensive drugs and the required use of CPAP/BiPAP at 12 months postoperative compared to the baseline as a proxy to type 2 diabetes mellitus, hypertension, and OSA improvement, respectively.

A systematic review including six cohort studies showed long-term (range 5 to 15 years) increased type 2 diabetes mellitus remission (relative risk $=5.90 ; 95 \%$ CI 3.75 to 9.28 ) after bariatric surgery as compared to non-surgical treatment [4]. We found $76 \%$ of type 2 diabetes mellitus remission without pharmacological therapy 12 months after surgery. Panunzi et al. [19] found $64 \%$ of type 2 diabetes mellitus remission 2 years after bariatric surgery.

Regarding systemic arterial hypertension, a randomized clinical trial assessed the impact of RYGB plus medical therapy versus medical therapy alone and found that patients in the surgical group were six times more likely to reduce $\geq 30 \%$ of total number of antihypertensive drugs 1 year after the surgery, whereas $51 \%$ presented hypertension remission [20]. In our sample, $54 \%$ of hypertensive patients were free of antihypertensive medications at 12 months and $49.4 \%$ showed hypertension remission.

Obesity is recognized as a major risk for OSA and its prevalence is higher than $60 \%$ in the bariatric surgery population $[40,41]$. However, in this study, we found a lower prevalence of OSA $(27 \%)$. In our center, only patients who screen positive for STOP-BANG questionnaire are referred to polysomnography test and it is likely that OSA asymptomatic patients have undergone the surgery $[42,43]$. Thus, we assessed the required use of CPAP/BiPAP prior and after surgery as a proxy to OSA improvement in the predictive model of success.

This study has inherent limitations related to its observational design and missing data. Moreover, the generalizability of this study is limited because only RYGB is offered in our institution. The strengths are the novelty of data mining and the robust statistical methodology which was succeed on its purpose. The PLS model displayed a MAPE of 0.1121 in the test portion of the dataset, leading to accurate predictions of postoperative outcomes. The composite indicator presented on Table 4 clearly shows that the high-success level comprises patients with greater number of comorbidities, whereas class III obesity was homogeneously distributed into the three success groups.

Hence, our clinical composite indicator to predict success based on preoperative characteristics allows prioritizing patients with best indication for bariatric surgery and could be incorporated in the public health system as a support tool in the decision-making process, possibly leading to lower healthcare costs and mortality.

\section{Conclusion}

This study developed and validated an accurate predictive model that comprises the sum of five outcome variables to predict success in bariatric surgery based exclusively on patients' preoperative characteristics. Preoperative predictors of success after bariatric surgery included lower age, presence of NAFLD and OSA, more years of CPAP/BiPAP use, negative history of cardiovascular disease, and lower number of antihypertensive drugs. The success index may help in prioritizing eligible patients waiting for bariatric surgery with the highest indication for the procedure and should be considered for incorporation in the public health system as a support tool in the decision-making process.

Supplementary Information The online version contains supplementary material available at https://doi.org/10.1007/s11695-020-05103-0.

Funding This study was supported by The National Council of Technological and Scientific Development (CNPq), by the Coordenação de Aperfeiçoamento de Pessoal de Nível Superior-Brazil (CAPES) - Finance Code 001, and by Fundo de Incentivo à Pesquisa e Eventos (FIPE) of Hospital de Clínicas de Porto Alegre.

\section{Compliance with Ethical Standards}

Conflict of Interest The authors declare that they have no conflicts of interest.

Ethical Approval All procedures performed in studies involving human participants were in accordance with the ethical standards of the 
institutional and/or national research committee and with the 1964 Helsinki Declaration and its later amendments or comparable ethical standards.

\section{References}

1. World Health Organization. Noncommunicable Diseases Progress Monitor 2020. Geneva; 2020. Licence: CC BY-NC-SA 3.0 IGO.

2. Blüher M. Obesity: global epidemiology and pathogenesis. Nat Rev Endocrinol. 2019;15(5):288-98.

3. Fontaine KR, Redden DT, Wang C, et al. Years of life lost due to obesity. JAMA. 2003;289(2):187-93.

4. Sheng B, Truong K, Spitler H, et al. The long-term effects of bariatric surgery on type 2 diabetes remission, microvascular and macrovascular complications, and mortality: a systematic review and meta-analysis. Obes Surg. 2017;27(10):2724-32.

5. Jakobsen GS, Småstuen MC, Sandbu R, et al. Association of bariatric surgery vs medical obesity treatment with long-term medical complications and obesity-related comorbidities. JAMA. 2018;319(3):291-301.

6. National Institutes of Health. Gastrointestinal surgery for severe obesity. Consensus Development Conference Panel. Ann Intern Med. 1991;115(12):956-61.

7. Christou NV, Efthimiou E. Bariatric surgery waiting times in Canada. Can J Surg. 2009;52(3):229-34.

8. Cohen RV, Luque A, Junqueira $S$, et al. What is the impact on the healthcare system if access to bariatric surgery is delayed? Surg Obes Relat Dis. 2017;13(9):1619-27.

9. Alvarez R, Bonham AJ, Buda CM, et al. Factors associated with long wait times for bariatric surgery. Ann Surg. 2019;270(6):1103-9.

10. Arteaga-González IJ, Martín-Malagón AI, Ruiz de Adana JC, et al. Bariatric surgery waiting lists in Spain. Obes Surg. 2018;28(12): 3992-6.

11. Flanagan E, Ghaderi I, Overby DW, et al. Reduced survival in bariatric surgery candidates delayed or denied by lack of insurance approval. Am Surg. 2016;82(2):166-70.

12. Padwal RS, Klarenbach SW, Wang X, et al. A simple prediction rule for all-cause mortality in a cohort eligible for bariatric surgery. JAMA Surg. 2013;148(12):1109-15.

13. Padwal RS, Pajewski NM, Allison DB, et al. Using the Edmonton obesity staging system to predict mortality in a populationrepresentative cohort of people with overweight and obesity. CMAJ. 2011;183(14):E1059-66.

14. DeMaria EJ, Portenier D, Wolfe L. Obesity surgery mortality risk score: proposal for a clinically useful score to predict mortality risk in patients undergoing gastric bypass. Surg Obes Relat Dis. 2007;3(2):134-40.

15. Stenberg E, Cao Y, Szabo E, et al. Risk prediction model for severe postoperative complication in bariatric surgery. Obes Surg. 2018;28(7):1869-75.

16. Collins GS, Reitsma JB, Altman DG, et al. Transparent reporting of a multivariable prediction model for individual prognosis or diagnosis (TRIPOD). Ann Intern Med. 2015;162(10):735-6.

17. World Health Organization. Physical status: the use and interpretation of anthropometry. WHO Technical Report Series 854. Geneva; 1995.

18. Doumouras AG, Hong D, Lee Y, et al. Association between bariatric surgery and all-cause mortality: a population-based matched cohort study in a universal health care system. Ann Intern Med. 2020; https://doi.org/10.7326/M19-3925.

19. Panunzi S, Carlsson L, De Gaetano A, et al. Determinants of diabetes remission and glycemic control after bariatric surgery. Diabetes Care. 2016;39(1):166-74.
20. Schiavon CA, Bersch-Ferreira AC, Santucci EV, et al. Effects of bariatric surgery in obese patients with hypertension: the GATEWAY randomized trial (Gastric Bypass to Treat Obese Patients With Steady Hypertension). Circulation. 2018;137(11): 1132-42.

21. Schiavon CA, Bhatt DL, Ikeoka D, et al. Three-year outcomes of bariatric surgery in patients with obesity and hypertension: a randomized clinical trial. Ann Intern Med. 2020;173(9):685-93.

22. Ashrafian H, Toma T, Rowland SP, et al. Bariatric surgery or nonsurgical weight loss for obstructive sleep apnoea? A systematic review and comparison of meta-analyses. Obes Surg. 2015;25(7): $1239-50$.

23. Whelton PK, Carey RM, Aronow WS, et al. 2017 ACC/AHA/ $\mathrm{AAPA} / \mathrm{ABC} / \mathrm{ACPM} / \mathrm{AGS} / \mathrm{APhA} / \mathrm{ASH} / \mathrm{ASPC} / \mathrm{NMA} / \mathrm{PCNA}$ guideline for the prevention, detection, evaluation, and management of high blood pressure in adults: a report of the American College of Cardiology/American Heart Association Task Force on Clinical Practice Guidelines. Circulation. 2018;138(17):e484 594.

24. American Diabetes Association. Classification and Diagnosis of Diabetes: Standards of Medical Care in Diabetes - 2020. Diabetes Care. 2020;43(Suppl 1):S14-31.

25. Grundy SM, Stone NJ, Bailey AL, et al. 2018 AHA/ACC/ AACVPR/AAPA/ABC/ACPM/ADA/AGS/APhA/ASPC/NLA/ PCNA guideline on the management of blood cholesterol: a report of the American College of Cardiology/American Heart Association Task Force on Clinical Practice Guidelines. Circulation. 2019;139(25):e1082-e143.

26. Laratta CR, Ayas NT, Povitz M, et al. Diagnosis and treatment of obstructive sleep apnea in adults. CMAJ. 2017;189(48):E1481-E8.

27. Kleiner DE, Brunt EM, Van Natta M, et al. Design and validation of a histological scoring system for nonalcoholic fatty liver disease. Hepatology. 2005;41(6):1313-21.

28. Chalasani N, Younossi Z, Lavine JE, et al. The diagnosis and management of nonalcoholic fatty liver disease: practice guidance from the American Association for the Study of Liver Diseases. Hepatology. 2018;67(1):328-57.

29. Global BMI Mortality Collaboration, Di Angelantonio E, Bhupathiraju SN, et al. Body-mass index and all-cause mortality: individual-participant-data meta-analysis of 239 prospective studies in four continents. Lancet. 2016;388(10046):776-86.

30. Pories WJ, Dohm LG, Mansfield CJ. Beyond the BMI: the search for better guidelines for bariatric surgery. Obesity (Silver Spring). 2010;18(5):865-71

31. Casimiro Pérez JA, Fernández Quesada C, Del Val Groba Marco $\mathrm{M}$, et al. Obesity Surgery Score (OSS) for prioritization in the bariatric surgery waiting list: a need of public health systems and a literature review. Obes Surg. 2018;28(4):1175-84.

32. Whitty JA, Ratcliffe J, Kendall E, et al. Prioritising patients for bariatric surgery: building public preferences from a discrete choice experiment into public policy. BMJ Open. 2015;5(10):e008919.

33. Rubino F, Cohen RV, Mingrone G, et al. Bariatric and metabolic surgery during and after the COVID-19 pandemic: DSS recommendations for management of surgical candidates and postoperative patients and prioritisation of access to surgery. Lancet Diabetes Endocrinol. 2020;8(7):640-8.

34. Pirlet C, Biertho L, Poirier P, et al. Comparison of short and long term cardiovascular outcomes after bariatric surgery in patients with vs without coronary artery disease. Am J Cardiol. 2020;125(1):40 7.

35. Delling L, Karason K, Olbers T, et al. Feasibility of bariatric surgery as a strategy for secondary prevention in cardiovascular disease: a report from the Swedish obese subjects trial. J Obes. 2010;2010:1-6. 
36. Gill RS, Majumdar SR, Wang X, et al. Prioritization and willingness to pay for bariatric surgery: the patient perspective. Can J Surg. 2014:57(1):33-9.

37. Sjöström L, Peltonen M, Jacobson P, et al. Bariatric surgery and long-term cardiovascular events. JAMA. 2012;307(1):56-65.

38. Sjöström L. Review of the key results from the Swedish Obese Subjects (SOS) trial - a prospective controlled intervention study of bariatric surgery. J Intern Med. 2013;273(3):219-34.

39. Lee Y, Doumouras AG, Yu J, et al. Complete resolution of nonalcoholic fatty liver disease after bariatric surgery: a systematic review and meta-analysis. Clin Gastroenterol Hepatol. 2019;17(6): 1040-60.e11.

40. Horvath CM, Jossen J, Kröll D, et al. Prevalence and prediction of obstructive sleep apnea prior to bariatric surgery-gender-specific performance of four sleep questionnaires. Obes Surg. 2018;28(9): $2720-6$.
41. Kositanurit W, Muntham D, Udomsawaengsup S, et al. Prevalence and associated factors of obstructive sleep apnea in morbidly obese patients undergoing bariatric surgery. Sleep Breath. 2018;22(1): 251-6.

42. O'Reilly E, Doherty L, O'Boyle C. How relevant is pre-operative obstructive sleep apnoea in the asymptomatic bariatric surgery patient? Obes Surg. 2020;30(3):969-74.

43. Duarte RLM, Fonseca LBM, Magalhães-da-Silveira FJ, et al. Validation of the STOP-Bang questionnaire as a means of screening for obstructive sleep apnea in adults in Brazil. J Bras Pneumol. 2017;43(6):456-63.

Publisher's Note Springer Nature remains neutral with regard to jurisdictional claims in published maps and institutional affiliations.

\section{Affiliations}

\section{Carina A. Blume ${ }^{1}$ (D) Priscila G. Brust-Renck ${ }^{2,3} \cdot$ Miriam K. Rocha $^{3,4} \cdot$ Gabriel Leivas $^{5}$ • Jeruza L. Neyeloff ${ }^{6}$. Michel J. Anzanello ${ }^{3}$. Flavio S. Fogliatto ${ }^{3}$ - Luciana R. Bahia ${ }^{6}$. Gabriela H. Telo ${ }^{7}$ Beatriz D. Schaan ${ }^{1,6,8}$}

1 Post-Graduate Program in Medical Sciences: Endocrinology, Universidade Federal do Rio Grande do Sul, Porto Alegre, RS, Brazil

2 Graduate School of Psychology, Universidade do Vale do Rio dos Sinos, São Leopoldo, RS, Brazil

3 Industrial \& Transportation Eng. Department, Universidade Federal do Rio Grande do Sul, Porto Alegre, RS, Brazil

4 Center of Engineering, Universidade Federal Rural do Semi-Árido, Mossoró, RN, Brazil
5 School of Medicine, Universidade Federal do Rio Grande do Sul, Porto Alegre, RS, Brazil

6 National Institute of Science and Technology for Health Technology Assessment (IATS), Hospital de Clínicas de Porto Alegre, Porto Alegre, Brazil

7 School of Medicine/Graduate Program in Medicine and Health Sciences, Pontifícia Universidade Católica do Rio Grande do Sul, Porto Alegre, RS, Brazil

8 Endocrine Division, Hospital de Clínicas de Porto Alegre, Porto Alegre, RS, Brazil 